\title{
Leser-Trélat Syndrome in a Male with Breast Carcinoma and Eyelid Basal Cell Carcinoma
}

\author{
Rajiv Garg ${ }^{a}$ Siddharth Madan ${ }^{a}$ Pragya Prakash ${ }^{a} \quad$ Ram Chander ${ }^{b}$ \\ Monisha Choudhary ${ }^{c}$ \\ Departments of a Ophthalmology, ${ }^{b}$ Dermatology, and ${ }^{\mathrm{C} P a t h o l o g y, ~ L a d y ~ H a r d i n g e ~ M e d i c a l ~ C o l l e g e ~ a n d ~}$ \\ Associated S.S.K.H \& K.S. Hospital, University of Delhi, New Delhi, India
}

\section{Established Facts}

- Leser-Trélat sign is associated with underlying visceral malignancies.

- Intraoperative frozen section control in eyelid malignancies has a pivotal role in limiting tumor recurrence.

\section{Novel Insights}

- This is possibly the first case report of eyelid basal cell carcinoma being associated with Leser-Trélat syndrome in a patient with breast carcinoma.

- A Tenzel semicircular flap can help correct extensive lid margin defects in lax eyelid tissues.

\section{Keywords}

Basal cell carcinoma · Leser-Trélat syndrome · Breast carcinoma $\cdot$ Eyelid malignancies $\cdot$ Tenzel flap

\section{Abstract \\ Purpose: Leser-Trélat syndrome consists of appearance of a solid tumor-like carcinoma breast, colon, or stomach follow- ing eruption of multiple seborrheic keratoses (SK) of the skin. We present an unusual and possibly the first case report of Leser-Trélat syndrome in a male patient with a history of mas- tectomy for breast carcinoma who presented to us with a sec-}

ond malignancy in the form of basal cell carcinoma (BCC) of the lower eyelid. Procedure: A 75-year-old male presented in 2014 with a history of modified radical mastectomy for infiltrating ductal carcinoma of the left breast which was performed 11 years prior to the day of presentation. Breast carcinoma was diagnosed following eruption of multiple SK at the same time. In the previous 3 years he noted a noduloulcerative growth over the lateral aspect of the right lower eyelid which was clinically diagnosed as BCC. Mass excision under frozen section control and lid reconstruction was performed. Diagnosis of BCC was confirmed on histopathological examination of the excised specimen. Results and

\section{KARGER}

(c) 2017 S. Karger AG, Basel

E-Mail karger@karger.com

www.karger.com/oop
Prof. Rajiv Garg

Department of Ophthalmology

Lady Hardinge Medical College and Associated S.S.K.H \& K.S. Hospital

University of Delhi, New Delhi 110001 (India)

E-Mail rajivgarg58@gmail.com 
Conclusions: Though a previously unobserved entity, our case supports the importance of Leser-Trélat sign and its relevance to affected individuals, as early recognition and prompt treatment of a low-stage cancer offers good prognosis.

(c) 2017 S. Karger AG, Basel

\section{Introduction}

Eruptive appearance of multiple seborrheic keratoses (SK) in association with underlying malignant disease characterizes Leser-Trélat syndrome, which is most commonly related to underlying visceral malignancies but rarely with adenocarcinoma of the breast [1-3].

\section{Observation}

A 75-year-old male presented to us with a gradually enlarging blackish painless growth over the lateral aspect of the right lower eyelid that was present for the past 3 years. A simultaneous increase in multiple skin lesions was observed all over the face and body which were dark brownish in appearance (Fig. 1a). The eyelid growth was the size of a pea at its onset and gradually increased to its present size. The growth measured more in the horizontal dimension than in the vertical extent. Modified radical mastectomy with axillary level 1,2, and 3 lymph node dissection had been performed 11 years prior for infiltrating ductal carcinoma of the left breast (stage III b, T4b N1M0). As per previous case records, multiple hyperpigmented dark brown raised lesions over the trunk, abdomen, scalp, and face, ranging in size from $1 \times 1 \mathrm{~mm}$ to a maximum diameter of $15 \times 15 \mathrm{~mm}$ (Fig. 1c, d) involving the scalp, face, chest, and abdomen, sparing bilateral palms and soles, were concurrently noted when the patient was diagnosed with breast carcinoma. These lesions were clinically suggestive of SK of the skin. Following mastectomy, he received 6 cycles of neoadjuvant chemotherapy (cyclophosphamide, Adriamycin, 5-fluorouracil) with radiotherapy (45 Gy over 25 days) along with hormone therapy. The patient's elder brother succumbed to breast carcinoma. His son developed some hematological malignancy in childhood which was treated adequately, yet no records were available for documentation.

General physical examination revealed a linear mastectomy scar over the left chest extending to the axilla with absence of nipple areola complex and multiple skin lesions as described in the previous paragraph. Dermatological opinion was sought and a scalp biopsy was taken from one of the lesions and subjected to histopathological examination. Hematoxylin and eosin stained sections revealed stratified squamous keratinized epithelium with acanthotic epidermis associated with papillomatosis, hyperkeratosis, and invaginations forming horn cysts. The tumor cells called the "basaloid" cells appeared similar to the basal cells of the epidermis. Squamous cells constituted the other cellular component. Hyperpigmentation of the basal layer was observed and all these features were suggestive of SK (Fig. 2a), for which no active intervention was advised.
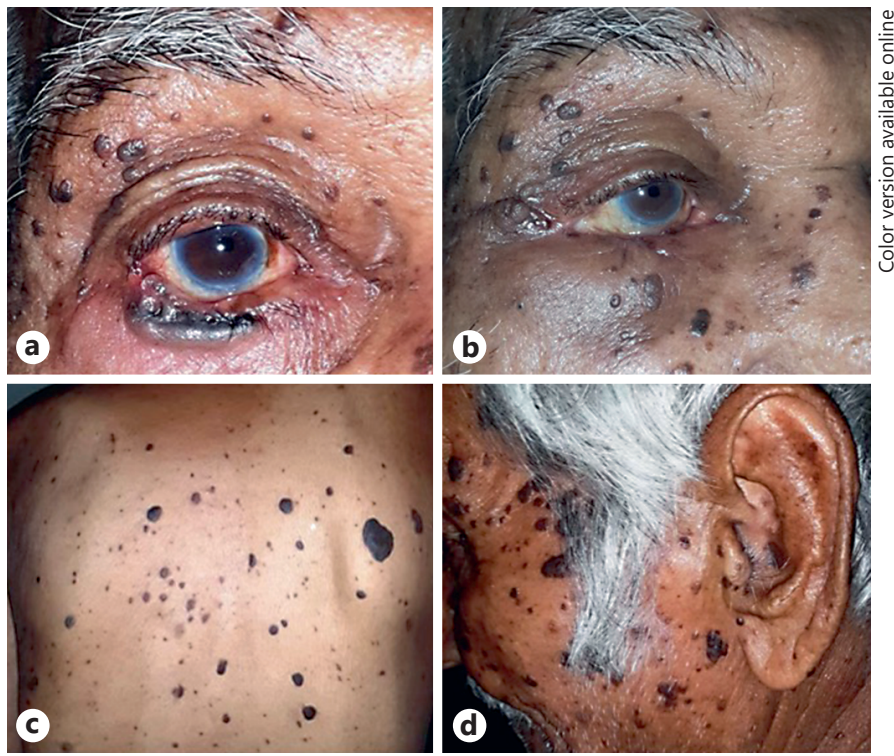

Fig. 1. a-d Right lower eyelid basal cell carcinoma, after lid reconstruction; seborrheic keratoses on the back and face.

Best corrected visual acuity was $6 / 9$ in the right eye and finger counting at $2 \mathrm{~m}$ in the left eye with accurate projection of rays in both the eyes. A single sessile growth in the right lower eyelid was observed. The growth measured 15 and $18 \mathrm{~mm}$ in inner and outer horizontal extent, respectively, with a vertical extent of $5 \mathrm{~mm}$. The growth was firm in consistency with an irregular surface and had a superficial ulceration and crater formation with typical rolled out margins along with a blackish discoloration of the overlying skin. The eyelid margin was thickened with loss of cilia. The growth extended to the posterior lid margin without any involvement of the inferior fornix. These clinical features were suggestive of basal cell carcinoma (BCC). The patient had no preauricular or regional lymphadenopathy. Both eyes were pseudophakic with a posterior chamber intraocular lens. The fundus examination in the right eye demonstrated a dull foveal reflex. The macula in the left eye revealed a healed scar of old choroiditis which accounted for the low vision in this eye.

The patient was a known case of coronary artery disease and was planned for the right lower eyelid mass excision under frozen section control with lid reconstruction under general anesthesia. Informed consent for a high-risk surgery was taken in view of the patient's cardiac status. Full-thickness resection of the lid tumor including an additional $3 \mathrm{~mm}$ of circumferential tissue was performed and the excised specimen was subjected to intraoperative frozen section examination. Involvement of the medial resected margin with the tumor was reported. The involved margin along with an additional $3 \mathrm{~mm}$ of the lid tissue was excised, but the puncta and lacrimal drainage apparatus was spared. This excised margin was reported free of the tumor tissue intraoperatively. A Tenzel semicircular myocutaneous flap was fashioned and a lateral canthoplasty was performed and the lid reconstruction was executed with a layered suture fixation and the eyelid anatomy was maintained (Fig. 1b). Histopathological examination of the paraffinembedded tissue sections from the excised specimen revealed BCC 

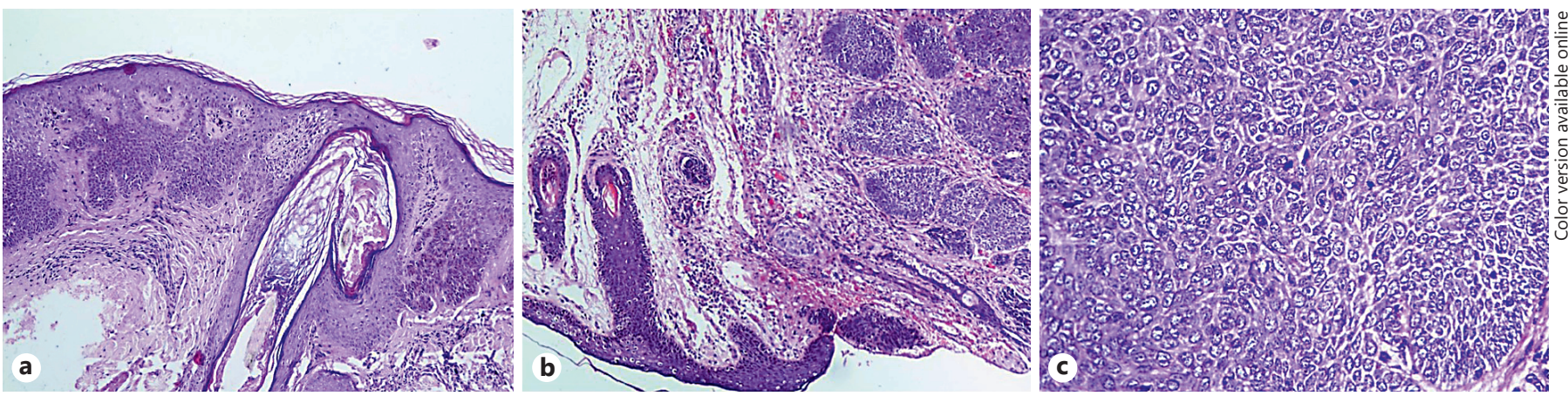

Fig. 2. a-c Seborrheic keratoses on scalp biopsy, nests of subepidermal malignant basaloid cells, and characteristic peripheral palisading with mitotic figures.

of the nodulo-ulcerative type (Fig. 2b, c) without involvement of the resected margins. There was enough lid laxity for the lower lid to be reconstructed primarily by the anterior lamella. Posterior lamella reconstruction was deferred because of the high risk associated with the general anesthesia on prolongation of surgical time.

\section{Discussion}

Eruptive appearance of multiple SK in association with underlying malignant disease characterizes Leser-Trélat sign [4-6]. In 1900, Hollander [7] first documented the possible association between worsening SK and underlying visceral malignancies. Various growth factors including epidermal growth factor and transforming growth factor- $\alpha$ function in a localized autocrine pathway specifically in the epidermal tissues and are responsible for hyperproliferative dermatologic lesions, namely SK [2]. Various paraneoplastic syndromes of the skin are associated with underlying malignancies as observed in reactive erythemas (necrolytic migratory erythema), musculoskeletal disorders (dermatomyositis, hypertrophic osteoarthropathy, clubbing), vascular dermatoses (Trousseau syndrome) and papulosquamous disorders (acanthosis nigricans, Bazex syndrome, and extramammary Paget disease) [4]. These paraneoplastic dermatoses usually disappear following tumor removal in about one-half of the patients and are seen to manifest coincidentally with tumor diagnosis [8]. In our patient, Leser-Trélat syndrome can be considered to have set in 11 years prior when the patient developed a breast lump which was subsequently evaluated and managed [9-11].

In their case report, Ponti et al. [4] described a patient with 6 malignancies including cutaneous BCC that appeared in the background of SK. They suggested that even
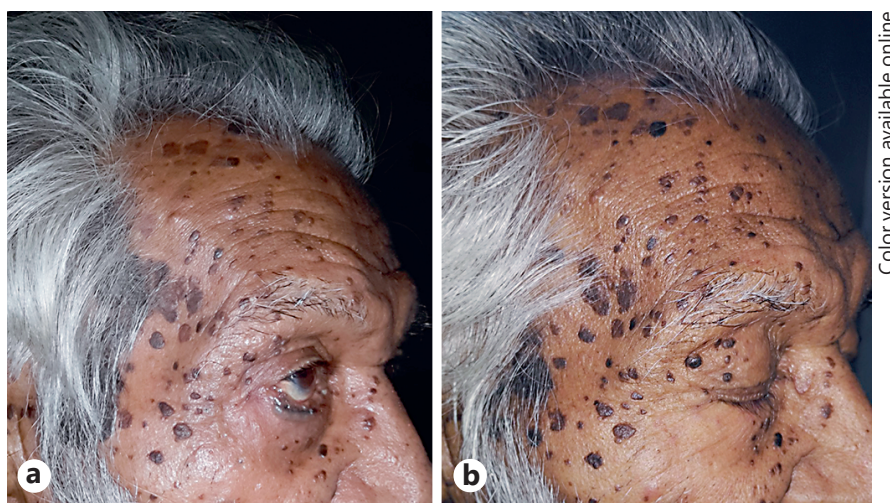

Fig. 3. Comparative patient photographs demonstrating lesions on the temporal aspect of forehead prior to basal cell carcinoma excision (a) and their absence and flattening in the similar location after surgery (b).

in the presence of Leser-Trélat sign confirmed by diagnosis of anamnestic or recent malignancies, a comprehensive multisystem evaluation should be executed for potentially multiple primitive and systemic malignancies [4]. Endogenous factors including the growth factors that could have possibly caused breast carcinoma in our patient may incite an epidermal malignancy via similar pathogenetic mechanisms. Ceylan et al. [12] reported a case of BCC in a patient with squamous cell carcinoma of the lung with multiple SK and hypothesized about the role of these endogenous and exogenous factors in the development of BCC. In addition to Leser-Trélat syndrome, a second malignancy in the form of BCC of lower eyelid appeared in our patient. After a follow-up of 3 years from April 2014 to May 2017, the SK lesions were observed to flatten at places and a few lesions disappeared, more so in the region around the eyelid, suggesting a pos- 
sible reduction in the growth factor (epidermal growth factor) levels after BCC excision (Fig. 3a, b). Such reduction in SK lesions was not noticed by the patient following mastectomy. In this case, as tissue mobilization was mostly horizontal, it inflicted minimal vertical tension and almost no lower lid retraction or entropion, and therefore the Tenzel flap worked well (Fig. 1b). The semicircular flap technique requires selective lysis of the limbs of lateral canthal tendon with a skin-muscle flap fashioned semicircularly and its boundaries established by the lateral eyebrow and the arc made by the flap itself [13]. Reconstruction of one-half to more than three-fourths of the upper or lower eyelid can be achieved successfully without harvesting tissue from the eyelids, nose, ear, or mouth [13]. The lower eyelid laxity aided in the lid reconstruction without any significant postoperative lower eyelid entropion and hence averted the need for subjecting the patient to an extensive reconstructive procedure, taking his cardiac status into consideration. Appropriate dermatologic examination is warranted in all cases of abrupt eruption or intensification of chronic SK in order to evaluate the frequency of this association. This case, possibly unreported previously, highlights a rare association of Leser-Trélat syndrome with an anamnestic oncologic history developing a second malignancy in the form of BCC of the lower eyelid.

\section{Statement of Ethics}

The patient gave his informed consent and the study protocol was approved by the institute's committee on human research. There are no ethical issues related to this case report.

\section{Disclosure Statement}

The authors report no conflicts of interest.

\section{Financial Disclosure/Funding}

None for all the authors.

\section{References}

1 Schwengle LE, Rampen FH, Wobbes T: Seborrhoeic keratoses and internal malignancies. A case control study. Clin Exp Dermatol 1988; 13:177-179.

2 Grob JJ, Rava MC, Gouvernet J, Fuentes P, Piana L, Gamerre M, et al: The relation between seborrheic keratoses and malignant solid tumours. A case-control study. Acta Derm Venereol 1991;71:166-169.

3 Lindelöf B, Sigurgeirsson B, Melander S: Seborrheic keratoses and cancer. J Am Acad Dermatol 1992;26:947-950.

4 Ponti G, Luppi G, Losi L, Giannetti A, Seidenari S: Leser-Trélat syndrome in patients affected by six multiple metachronous primitive cancers. J Hematol Oncol 2010;3:2.
5 Schwartz RA: Sign of Leser-Trélat. J Am Acad Dermatol 1996;35:88-95.

6 Rampen HJ, Schwengle LE: The sign of LeserTrélat: does it exist? J Am Acad Dermatol 1989;21:50-55.

7 Hollander EV: Beiträge zur Frühdiagnose des Darmcarcinomas (Hereditätsverhältnisse und Hautveränderungen). Dtsch Med Wochenschr 1900;26:483-485.

8 Zaballos P, Salsench E, Serrano P, Cuellar F, Puig S, Malvehy J: Studying regression of seborrheic keratosis in lichenoid keratosis with sequential dermoscopy imaging. Dermatology 2010;220:103-109.

9 Venencie PY, Perry HO: Sign of Leser-Trélat: report of two cases and review of the literature. J Am Acad Dermatol 1984;10:83-88.
10 Shamsadini S, Wadji MB, Shamsadini A: Surrounding ipsilateral eruptive seborrheic keratosis as a warning sign of intraductal breast carcinoma and Paget's disease (Leser Trelat sign). Dermatol Online J 2006;12:27.

11 Stieler W, Plewig G: Acanthosis nigricans maligna and Leser-Trélat sign in double malignancy of the breast and stomach (in German). Z Hautkr 1987;62:344-366.

12 Ceylan C, Alper S, Kilinç I: Leser-Trelat sign. Int J Dermatol. 2002;41:687-688.

13 Tenzel RR, Stewart WB: Eyelid reconstruction by the semicircle flap technique. Ophthalmology 1978;85:1164-1169. 